\title{
Meige syndrome: double-blind crossover study of sodium valproate
}

\author{
J W SNOEK, T W VAN WEERDEN, A W TEELKEN, W VAN DEN BURG, \\ J P W F LAKKE
}

From the Department of Neurology, University Hospital, Groningen, The Netherlands

SUMMARY A double-blind crossover study of sodium valproate and placebo was conducted in five patients with Meige syndrome. CSF neurotransmitter studies were performed at the end of each treatment period. GABA levels were not influenced by the administration of sodium valproate. An increase in HVA levels was observed in every patient, which may reflect an increase in central dopaminergic activity. This finding may explain the trend towards clinical deterioration which was observed during treatment with sodium valproate. Sodium valproate appears to be ineffective in Meige syndrome.

Most pharmacological studies dealing with Meige syndrome (idiopathic or essential blepharospasm and oromandibular dystonia) have been based on the assumption of disruption of reciprocal dopaminergicacetylcholinergic influences in the basal ganglia. ${ }^{1-3}$ Treatment based on this assumption has yielded inconsistent results. ${ }^{4}$ Decreased CSF gamma-aminobutyric acid (GABA) levels in adult onset dystonia have been reported, ${ }^{5}$ suggesting central GABA deficiency in this group of disorders. Several uncontrolled studies employing GABA mimetic or facilitating agents in Meige syndrome with a favourable effect have been reported. ${ }^{6-9}$ Sodium valproate is a GABA mimetic agent ${ }^{10}$ and an increase in CSF GABA levels in humans during administration of sodium valproate in therapeutic doses has been reported. ${ }^{1112}$ We conducted a double-blind crossover study in five patients with Meige syndrome, in order to test the following hypothesis: sodium valproate has a beneficial effect in Meige syndrome by restoring decreased central GABA activity, which is demonstrable by an increase in CSF GABA levels during treatment.

\footnotetext{
Address for reprint requests: Dr Snoek, Department of Neurology, University Hospital Groningen, P.O. Box 30.001, 9700 RB Groningen, The Netherlands.
}

Received 20 February 1987.

Accepted 2 April 1987

\section{Methods}

Five patients with Meige syndrome gave informed consent for the trial. Individual characteristics are shown in the table. In accordance with Meige's original description, ${ }^{13}$ only patients with both blepharospasm and oromandibular dystonia were included; in all patients blepharospasm, interfering with normal vision, was the major symptom. Treatment periods with sodium valproate and placebo lasted 6 weeks and the sequence in which the drugs were administered was randomised. All other medication known to exert an influence on the central nervous system was stopped at least 2 weeks prior to the study. Sodium valproate was given three times daily in increasing doses up to $20 \mathrm{mg} / \mathrm{kg}$ at the end of the first week; an identical scheme was used for the placebo tablets. After 6 weeks the medication was discontinued and after a drug free interval of 2 weeks duration the next phase started with the same build up of medication. The patients were seen at 2-week intervals for evaluation and for medication adjustment by an independent clinician. Lumbar puncture was performed under standard conditions at the end of both treatment phases; on the same day, sodium valproate serum levels were monitored at 8 hour intervals.

Patients were admitted at least $\mathbf{2 4}$ hours prior to the lumbar punctures and started on a vanillyl mandelic acid (VMA) restricted diet. After a fasting and bedrest period of 12 hours lumbar puncture was carried out between 8 and 10 am with the patient in sitting position. CSF was acidified with 1 drop formic acid per $\mathrm{ml}$ and frozen at $-80^{\circ}$ in small portions.

The concentrations of 3-methoxy-4-hydroxyphenylglycol (MPHG), homovanillic acid (HVA), 5-hydroxy-indoleacetic acid (5-HIAA) and GABA were determined by high performance liquid chromatography (HPLC). MHPG, 
Table Patient characteristics

\begin{tabular}{lllll}
\hline Patient & Sex & Age at onset (yr) & Duration (yr) & Blepharospasm \\
\hline 1 & M & 57 & 5 & +++ \\
2 & F & 59 & 2 & ++ \\
3 & M & 45 & 3 & ++ \\
4 & F & 52 & 11 & ++ \\
5 & M & 58 & 3 & ++ \\
\hline
\end{tabular}

$+++=$ severe,$+=$ moderate, $+=$ mild .

HVA and 5-HIAA were estimated by separation on a Nucleosil C18 column (dim $3.0 \times 100 \mathrm{~mm})$ and electrochemical detection (EC) at a potential of $700 \mathrm{mV}$. The injection volume was $50 \mu \mathrm{l} \mathrm{CSF}$ and the elution buffer had a composition of $0.07 \mathrm{M}$ trichloroacetic acid, $0.03 \mathrm{M}$ sodium acetate, $10^{-4} \mathrm{M}$ EDTA, $\mathrm{pH}=4.0$, and $5 \%$ methanol. Flowrate was $0.40 \mathrm{ml} / \mathrm{min}$ and pressure about $7000 \mathrm{kPa}$. GABA was measured by separation on an ion exchange column (Dionex DC-4A; dim $5.0 \times 75 \mathrm{~mm}$ ) and fluorometric detection using the method of Böhlen et al ${ }^{14}$ with minor modifications. CSF samples were deproteinised with $12.5 \%$ 5-sulpho-salicylic acid $(4: 1 \mathrm{v} / \mathrm{v})$ and $100 \mu$ lof the supernatant was injected on the column. Elution was carried out with $0.067 \mathrm{M}$ sodium citrate at $\mathrm{pH} 4.50$ and detection after reaction with o-phtaldialdehyde. Flowrate was $0.50 \mathrm{ml} / \mathrm{min}$ and pressure about $200-250 \mathrm{kPa}$.

Assessment of the effect of treatment was based on a quadruple scoring system: (1) subjective scoring of abnormal movements, (2) clinical scoring of abnormal movements, (3) blind rating of randomised surface EMG recordings and (4) blind rating of randomised video tapes. All patients rated the severity of their symptoms everyday on a scale of 0 to 10 ; only the scores of the 2-weekly examination dates were taken into account. Dystonic movements were assessed by the senior author separately in upper and lower face and rated for severity: 0 = absent, $1=$ mild, 2 = moderate, $3=$ severe. Surface EMG recordings and videotapes were made on each examination with the patients in standardised postures (that is, at rest, reading aloud and attempting to suppress the abnormal movements, for 1 minute each). All EMG recordings were made using surface electrodes placed on frontal, orbicularis oculi, orbicularis oris and platysma muscles. Recordings were randomised and rated by a neurophysiologist blinded to the names of the patients and the medications administered. Likewise, the randomised videotapes were independently scored by two raters.

For each evaluation variable, scores were ranked from best to most severe (6-1) for each patient. The summed ranks within the placebo and sodium valproate groups were then compared.

\section{Results}

Treatment with sodium valproate at therapeutic serum levels (mean: $79 \cdot 3 \mu \mathrm{g} / \mathrm{ml}$, range: $44-128 \mu \mathrm{g} / \mathrm{ml}$ ) did not result in clinical improvement (fig 1 ). In fact, in all comparisons sodium valproate was slightly inferior to placebo. Mean CSF GABA levels were not decreased below reference values in the placebo phase and no increase was observed during treatment with

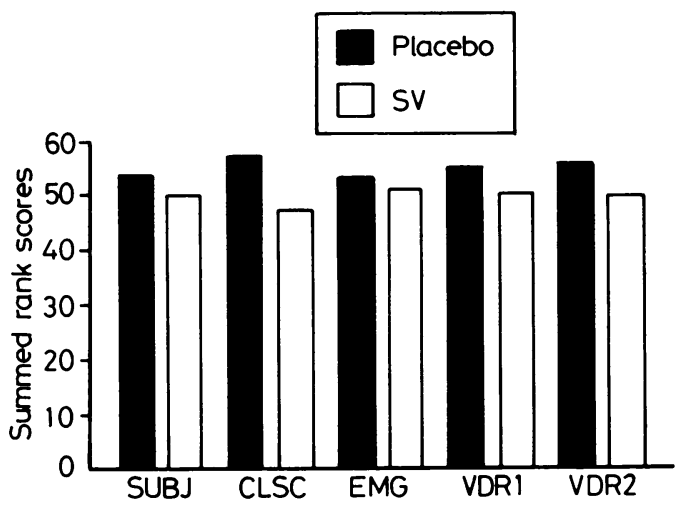

Fig 1 Comparative efficacy of sodium valproate ( $S V$ ) and placebo in five patients with Meige syndrome. Evaluation variables: (1) subjective scoring of abnormal movements (SUBJ); (2) clinical scoring of abnormal movements (CLSC); (3) blind rating of randomised surface EMG recordings (EMG); (4) blind rating of randomised video tapes by 2 independent raters (VDR1 and VDR2). For each patient scores have been rated from best to most severe (6-1) for each evaluation variable and within each treatment condition these rank scores have been summed.

sodium valproate (fig 2a). However, CSF HVA levels increased in all patients during treatment with sodium valproate $(p=0.03$ on the assumption of no effect on HVA level) (fig 2b). No significant effect was observed on both MHPG and 5-HIAA levels, but mean baseline (placebo) MHPG levels were elevated above reference control values (fig $2 \mathrm{c}$ ).

\section{Discussion}

The cause of Meige syndrome, a disabling condition, has yet to be established. ${ }^{15}$ Recent research suggests an increased excitability of the interneurons of the blink and corneal reflexes, probably due to a hitherto undetected basal ganglia disorder. ${ }^{16}$ Symptomatic blepharospasm has been observed in patients with brain stem lesions, ${ }^{17}$ communicating hydrocephalus, ${ }^{18}$ and bilateral basal ganglia infarction. ${ }^{19}$ Drug treatment of blepharospasm and/or oromandibular dystonia remains unsatisfactory, ${ }^{4} 152021$ although effectiveness has been claimed of such 

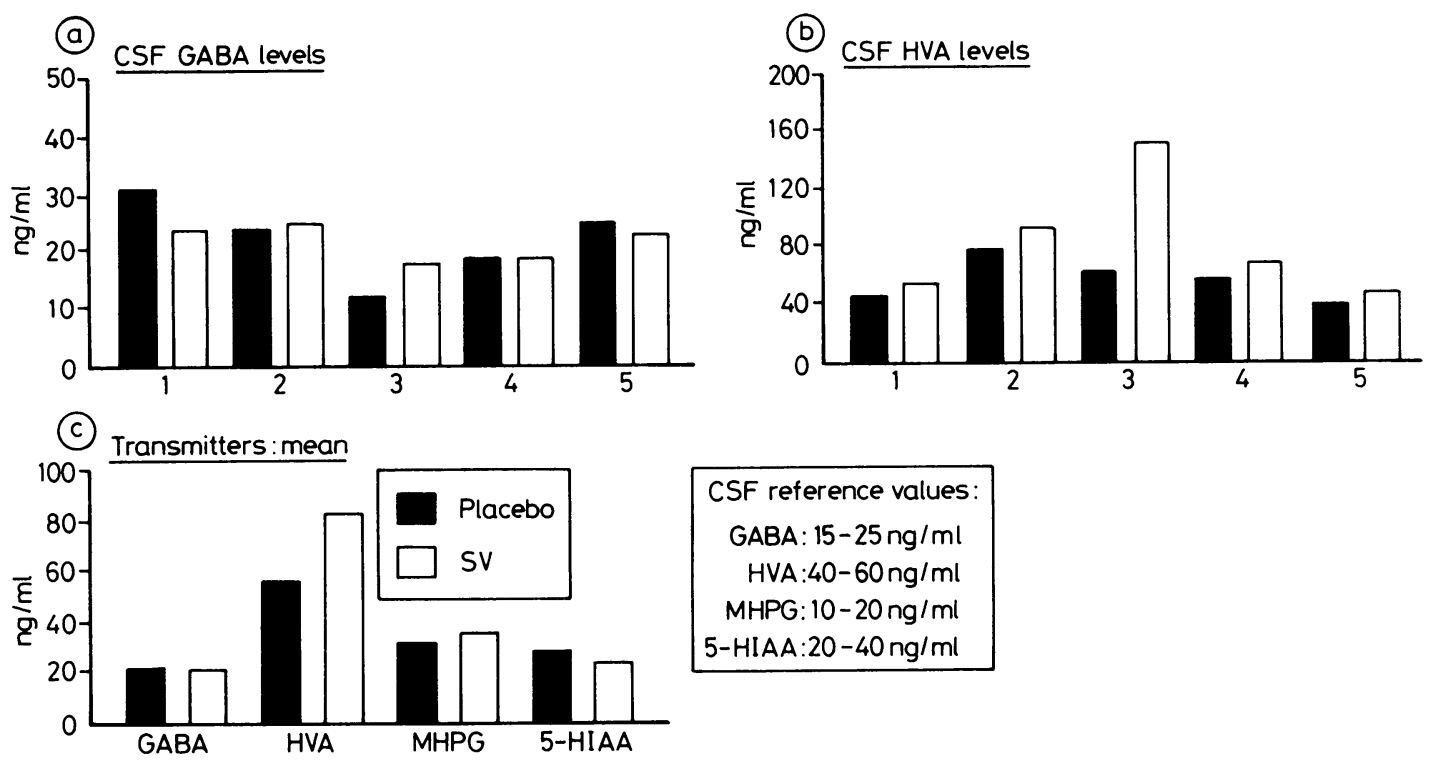

Fig 2 CSF neurotransmitter levels during treatment with sodium valproate (SV) and placebo in five patients with Meige syndrome.

different compounds as cholinergics, ${ }^{22}$ and anticholinergics, ${ }^{282324}$ dopamine agonists, ${ }^{24-26}$ and antagonists, ${ }^{1} 28222427$ benzodiazepines, ${ }^{6} 924$ baclofen, ${ }^{827}$ lithium, ${ }^{24}$ choline, ${ }^{28}$ and cannabidiol. ${ }^{29}$ Most studies have dealt with attempts to manipulate either the dopamine or acetylcholine systems of the brain, but there appears to be no consistent pharmacologic response. ${ }^{24}$

Recently, the role of GABA in a variety of dystonic and hyperkinetic movement disorders has been stressed. ${ }^{30-32}$ Neophytides et al reported decreased CSF GABA concentrations in adult-onset dystonia, ${ }^{5}$ of which Meige syndrome is regarded a manifestation. ${ }^{33}$ In one uncontrolled study, ${ }^{7}$ treatment of a patient with Meige syndrome with a combination of sodium valproate and baclofen resulted in "substantial improvement". Sodium valproate appears to be effective in reducing symptoms in tardive dyskinesia,$^{3034}$ a disorder which may be clinically indistinguishable from Meige syndrome. ${ }^{13536}$ Sodium valproate may exert its influence on GABAergic mechanism via direct GABA transaminase inhibition, but, more likely, by an effect on a postsynaptic element, probably the GABA receptor complex. ${ }^{10}$ There is, however, some doubt whether doses used in the treatment of patients are large enough to affect brain GABA. ${ }^{37}$ CSF GABA levels have been found to be increased by administration of sodium valproate in therapeutic doses, ${ }^{11} 12$ but unchanged CSF GABA levels have also been reported. ${ }^{5}$ We were unable to confirm the finding of decreased (placebo) GABA levels in our patients, and no increase was observed during treatment with sodium valproate. One of our reasons for investigating the efficacy of sodium valproate in Meige syndrome was the theory that this disorder is due to a reduction in central GABA mediated inhibition, resulting in striatal dopaminergic predominance, secondary to disinhibition of dopaminergic nigral neurons. ${ }^{17}$ Accordingly, treatment with a GABA mimetic or facilitating agent would be expected to result in clinical improvement. Recently, however, evidence has been presented for the opposite phenomenon: ${ }^{38}$ as the threshold dose of GABA receptor agonists for inhibiting striatal acetylcholine neurons is substantially lower than that for depressing dopamine cells, low doses of these agents may selectively reduce stria-tal cholinergic activity in the absence of changes in dopaminergic transmission, thus resulting in a net dopaminergic preponderance. We did observe an increase in CSF HVA levels during treatment with sodium valproate. This also suggests an increase in the dopaminergic activity in the brain during treatment with sodium valproate ${ }^{11}$ and may explain the trend towards clinical deterioration we observed in our patients.

In conclusion, there appear to be no reasons to investigate further the use of sodium valproate in the treatment of Meige syndrome. 
The authors thank Professor $\mathrm{H}$ Wesseling, for his helpful comments on the design of the study; Dr OG Sie, who acted as independent clinician; Dr DRA Uges, for the sodium valproate serum concentration measurements; Mr R Portegies for the surface EMG recordings; $\mathrm{Mr} \mathrm{C}$ Dobma for the video recordings, and $\mathrm{Mr} \mathbf{J J}$ Hoks for preparation of the figures. The sodium valproate and placebo tablets were supplied by Sanofi Labaz, Maassluis, The Netherlands.

\section{References}

1 Tolosa ES, Lai C. Meige disease: striatal dopaminergic preponderance. Neurology 1979:29:1126-30.

2 Stahl SM. Berger PA. Bromocriptine, physostigmine. and neurotransmitter mechanisms in the dystonias. Neurology 1982:32:889-92.

3 Ortiz A. Neuropharmacological profile of Meige's disease: overview and a case report. Clin Neuropharmacol 1983;6:297-304.

4 Marsden CD, Lang AE, Sheehy MP. Pharmacology of cranial dystonia. Neurology 1983;33:1100-1.

5 Neophytides A. Suria A, Chase TN. Cerebrospinal fluid GABA in neurological disease. Neurology 1978;28:359.

6 Merikangas JR, Reynolds CF. Blepharospasm: successful treatment with clonazepam. Ann Neurol 1979:5:401-2

7 Brennan MJW, Ruff P. Sandyk R. Efficacy of a combination of sodium valproate and baclofen in Meige's disease (idiopathic orofacial dystonia). Br Med J 1982;285:853.

8 Gollomp SM, Fahn S, Burke RE, Reches A, Ilson J. Therapeutic trials in Meige syndrome. In: Fahn S. Calne DB, Shoulson I. Experimental Therapeutics of Movement Disorders. Advances in Neurology, vol 37. New York: Raven Press, 1983:207-13.

9 Hipola D. Mateo D, Gimenéz-Roldán. Meige’s syndrome: acute and chronic responses to clonazepam and anticholinergics. Eur Neurol 1984:23:474-8.

10 Spero L. Neurotransmitters and CNS disease: epilepsy. Lancet 1982:2:1319-22.

II Zimmer R. Teelken AW. Gündürewa M. Rüther E. Cramer H Effect of sodium-valproate on CSF GABA, cAMP, cGMP and homovanillic acid levels in men. Brain Res Bull 1980;5:585-8.

12 Löscher W, Siemes H. Valproic acid increases gammaaminobutyric acid in CSF of epileptic children. Lance 1984;ii:225.

13 Tolosa ES. Klawans HL. Meige's disease. A clinical form of facial convulsion, bilateral and medial. Arch Neurol 1979;36:635-7.

14 Böhlen P. Schechter PJ, van Damme W, Coquillat G, Dosch JC Koch-Wesser J. Automated assay of gamma-amino-butyric acid in human cerebrospinal fluid. Clin Chem 1978;24:256-60.

15 Lees AJ. The adult onset focal dystonias, chap 11. In: Tics and Related Disorders. London: Churchill Livingstone. 1985:142-55.

16 Berardelli A. Rothwell JC, Day BL. Marsden CD. Pathophysiology of blepharospasm and oromandibular dystonia. Brain 1985:108:593-608
17 Jankovic J, Patel SC. Blepharospasm associated with brainstem lesions. Neurology 1983;33:1237-40.

18 Lange AE, Sharpe JA. Blepharospasm associated with palatal myoclonus and communicating hydrocephalus. Neurology 1984;34:1522-3

19 Keane JR, Young JA. Blepharospasm with bilateral basal ganglia infarction. Arch Neurol 1985;42:1206-8.

20 Chopra JS, Radhakrishnan K, Sridharan R. Meige's syndrome: clinical, pharmacological and radiological observations. Clin Neurol Neurosurg 1981;83:145-52.

21 Snoek JW, van Weerden TW, Lakke JPWF. Meige syndrome: review of 8 cases. Clin Neurol Neurosurg 1985;87:236-7.

22 Casey DE. Pharmacology of blepharospasm-oromandibular dystonia syndrome. Neurology 1980;30:690-5.

23 Tanner CM, Glantz RH, Klawans HL. Meige disease: acute and chronic cholinergic effects. Neurology 1982;32:783-5.

24 Jankovic J, Ford J. Blepharospasm and orofacial-cervical dystonia: clinical and pharmacological findings in 100 patients. Ann Neurol 1983:13:402-11.

25 Micheli F, Fernández Pardal MM. Leiguarda RC. Beneficial effects of lisuride in Meige disease. Neurology 1982:32:432-4.

26 Quinn NP. Lang AE. Sheehy MP, Marsden CD. Lisuride in dystonia. Neurology 1985;35:766-9.

27 Fahn S, Bressman S, Burke R, Hening W, Ilson J, Walters A. Treatment of blepharospasm with high-dose baclofen. Ann Neurol 1983;14:106.

28 Skarf JB, Sharpe JA. Choline for blepharospasm. Lancet 1981:2:957-8.

29 Snider SR, Consroe P. Treatment of Meige syndrome with cannabidiol. Neurology 1984;34(suppl 1): 147.

30 Meldrum B. Pharmacology of GABA. Clin Neuropharmacol 1982:5:293-316.

31 Mondrup K. Dupont E, Braendgaard H. Progabide in the treatment of hyperkinetic extrapyramidal movement disorders. Acta Neurol Scand 1985;72:341-3.

32 Stahl SM, Thornton JE, Simpson ML, Berger PA. Gamma-vinyl GABA in tardive dyskinesia and other movement disorders. Neurology 1984:34(suppl 1):85-6.

33 Marsden CD. Blepharospasm-oromandibular dystonia syndrome (Brueghel's syndrome). J Neurol Neurosurg Psychiatry 1976;39:1204-9.

34 Casey DE, Hammerstad JP. Sodium valproate in tardive dyskinesia. J Clin Psychiatry 1979;40:483-5.

35 Weiner WJ, Nausieda PA, Glantz RH. Meige syndrome (blepharospasm-oromandibular dystonia) after long-term neuroleptic therapy. Neurology 1981;31:1555-6.

36 Stahl SM, Yesavage JA, Berger PA. Pharmacologic characteristics of Meige dystonia: differentiation from tardive dyskinesia. J Clin Psychiatry 1982;43:445-6.

37 Johnston D. Valproic acid: update on its mechanisms of action. Epilepsia 1984:25(suppl 1):S1-24.

38 Bartholini G, Scatton B, Zivkovic B. Lloyd KG. GABA receptor agonists and extrapyramidal motor function: therapeutic implications for Parkinson's disease. In: Yahr MD, Bergmann KJ. Parkinson's disease. Advances in Neurology, vol. 45. New York: Raven Press, 1987:79-83. 